\title{
Effect of emissivity of roof-tile coatings on their efficiency to thermally isolate architectural structures
}

by Marija Strojnik

Optics Research Center, A. P. 1-948, 37000 Leon, Gto., Mexico, mstrojnik@gmail.com

\begin{abstract}
When assessing temperature-dependent emissivity for the improved architectural design, we must obtain accurate knowledge between the heat transfer from outside the architectural structure to the inside for different location of heating sources (solar irradiation from outside in summer, heaters from inside in winter).
\end{abstract}

\section{Introduction}

Designing materials with spectrally dependent thermal characteristics to act as barriers to heat transfer may reduce the energy consumption in homes and office buildings. Decreased absorptivity (or increased reflectivity) results in thermal structures insensitive to the heat flux either originating outside (Sun) or inside the structure (heating). Both of these thermal processes, and especially the former, add to the network load during the peak electricity demand.

\section{Material characterization}

Different types of roofing materials are currently employed to cover buildings and provide physical protection against elements. Only recently, more emphasis has started to be placed on the employment of the roofing materials that incorporate resistance to the absorption and heat transfer, either for solar radiation from the outside in summer or for inside-generated heat in winter. Using either brick possibly glazed and coated or especially finished concrete with color additives may accomplish this objective.

Figure 1a exhibits the solar spectral incidence, at the top and the bottom of the atmosphere. It is similar to that of a blackbody radiator at $5,800 \mathrm{~K}$, presented in Fig. 2a. A coating should ideally reflect radiation between $0.4 \mu \mathrm{m}$ and $1.7 \mu \mathrm{m}$ to decrease the amount of heat absorbed upon the Sun incidence on the roof. A room-temperature body at $315 \mathrm{~K}$ emits radiation with peak centered at around $10 \mu \mathrm{m}$, also indicated in Fig. 2a. Figure 1b shows solar spectral incidence and integrated solar incidence on the rooftop. Figure $2 \mathrm{~b}$ displays integrated radiance of the Sun at $5,800 \mathrm{~K}$ and rooftop at $315 \mathrm{~K}$.

The emissivity is equal to 1 minus reflectivity. Most surfaces are characterized by diffuse and specular component. Reflectance likely includes both of these components. All material, and especially the surface, characteristics depend on the actual piece, its history, environmental conditions and aging.

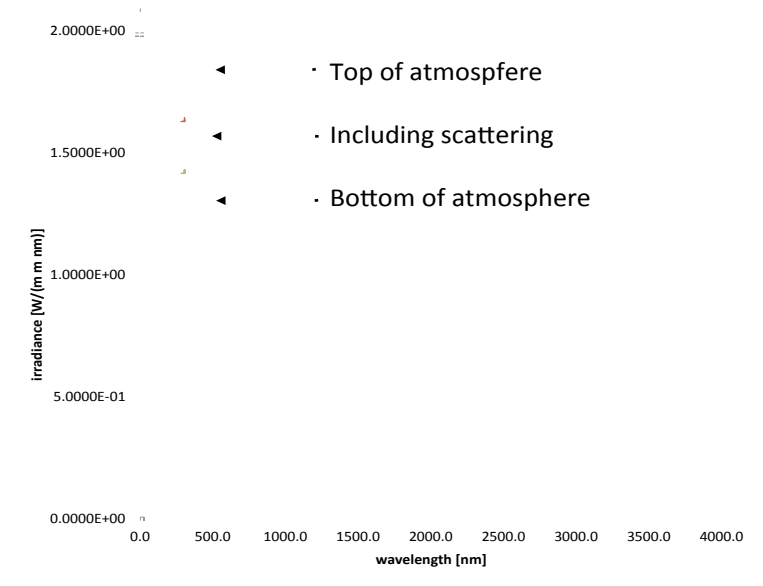

Fig. 1a. Solar spectral incidence at the top of the atmosphere, at the bottom of the atmosphere and the measured radiation that includes scattering.
Fig. 1b. Solar spectral incidence and integrated solar incidence on the rooftop. 


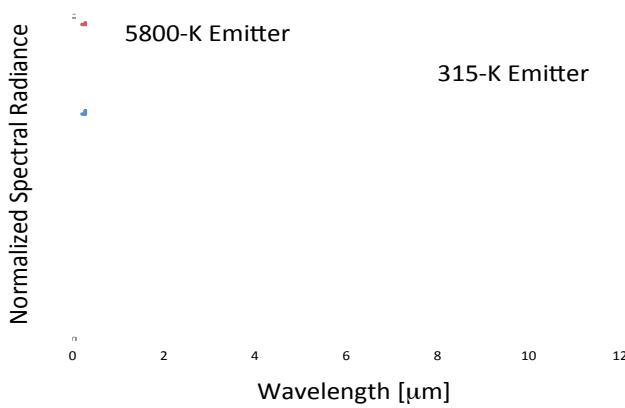

Fig. 2a. Solar spectral radiance, reduced by $10^{6}$, for a blackbody at 5,800 K (Sun) and $315 \mathrm{~K}$ (rooftop).

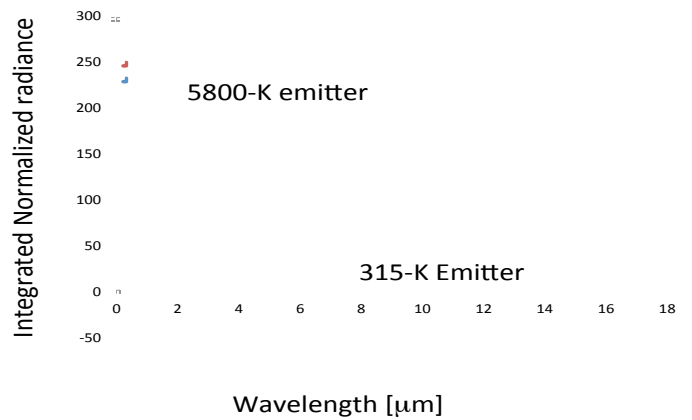

Fig. 2b. Integrated radiance of the Sun $(5,800 \mathrm{~K})$ and rooftop $(315 \mathrm{~K})$.

\section{Results}

Figure 5 shows the measured reflectivity including the specular component values. We observe that the increase in the coating thickness increases reflectivity (or, decreases emissivity) for all spectral regions of interest: visible, infrared, and combined. This means that the effect of increasing coating thickness is to decrease the broadband absorption, for all spectral intervals of interest. The greatest improvement is found when depositing a relatively thin coating, or increasing the coating thickness from $0 \mathrm{~mm}$ to about $0.1 \mathrm{~mm}$. In the visible region we observe a fairly flat response, independently of the coating thickness of about 0.94 [0.92 - 0.96], indicating "whiteness" of the response. The measurements correspond to an impressive value of 0.06 for emissivity in the visible. For wavelengths longer than $1.1 \mu \mathrm{m}(\mathrm{IR})$, the reflectance values are significantly lower. At about $0.1 \mathrm{~mm}$ coating thickness, the reflectivity in the visible of 0.92 decreases to 0.86 , or about $5 \%$ decreases. At coating thickness of about $0.5 \mathrm{~mm}$, where visible reflectivity achieves 0.97 , IR reflectivity is 0.95 , nearly the same. Average IR reflectivity of 0.92 may be compared with that in the visible of 0.94 .

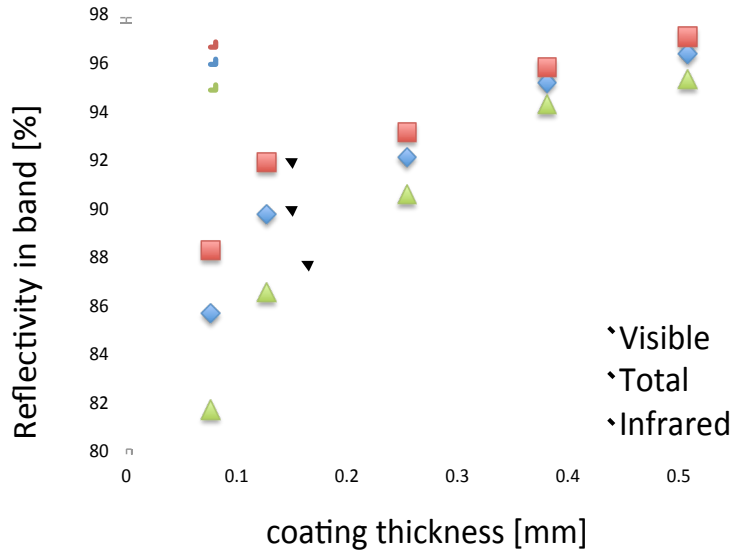

Fig. 3. Total reflectance in a band for UV-VIS-IR-, VISand $I R$ - region as a function of coating thickness.

\section{Conclusions}

A balance must be achieved between characteristics of the coating material to perform equally well in the visible and in IR. A more precise knowledge must be established between the heat transfer from outside the architectural structure to the inside for different location of heating sources (solar irradiation from outside in summer, heating stoves from inside in winter). The amount of reflected radiation is greatly dependent on the temperature; therefore knowledge of this parameter will significantly impact the heat transfer balances. The presence of coating is the most significant contribution to the emissivity decrease (low absorption), rather than its actual thickness.

\section{References}

1. Martin, H., "Heat and Mass Transfer between Impinging Gas Jets and Solid Surfaces," Advances in Heat Transfer, vol. 13, pp. 1 - 60, Academic Press, New York (1977).

2. Kaczmarek, M., Nowakowski, A., Suchowirski, M., Siebert, J., Stojek, W., "Active dynamic thermography in cardiosurgery," Quantitative InfraRed Thermography J. Vol. 4(1) pp. 107-123 (2007).

3. St-Laurent, L., Prévost, D., Maldague, X., "Fast and accurate calibration-based thermal/colour sensors registration," Proceedings of 10th Quantitative InfraRed Thermography conference, paper QIRT2010-126 Québec, Canada (2010).

4. Renkielska, A., Nowakowski, A., Kaczmarek, M., et al., "Burn depths evaluation based on active dynamic IR thermal imaging - a preliminary study," Burns. Vol. 32, pp. 867-875 (2006).

5. Maturilli, A., Helbert, J., "Characterization, testing, calibration, and validation of the Berlin database," JARS 8, 084985-1 to $084985-12$ (2014). 